\begin{tabular}{l} 
DE DE GRUYTER \\
\hline
\end{tabular}

\title{
DYNAMIC SIMULATOR-BASED APC DESIGN FOR A NAPHTHA REDISTILLATION COLUMN
}

\author{
LÁSzló Szabó, ${ }^{1 *}$ KlÁra Kubovicsné Stocz, ${ }^{1}$ LaURa Szabó, ${ }^{1}$ SÁndor NÉmeth, ${ }^{2}$ \\ AND FERENC SZEIFERT ${ }^{2}$ \\ ${ }^{1}$ Department of Technology and Development, MOL Plc., Olajmunkás u 2., Százhalombatta, \\ H-2443, HUNGARY \\ ${ }^{2}$ Department of Process Engineering, University of Pannonia, Egyetem u 10., Veszprém, \\ H-8200, HUNGARY
}

\begin{abstract}
In this simulation study the operation of a naphtha redistillation column (a column with two feeds and three products) was analyzed with the application of Aspen HYSYS ${ }^{\circledR}$ software. The simulator, structure of local controllers and the product-quality estimators were based on the data of an industrial column in the Danube Refinery. The aim of the analysis was to identify the dynamic and steady-state effects of heating and cooling as well as the sidestream of product qualities. The relationship between the tray temperatures and the quality of the products was also identified and inferential calculations were made. Based on the identified relationships, a twolevel hierarchical control structure was developed. On the lowest level of the hierarchy are the local controllers of flowrates, liquid levels, pressure and duty. The inferential calculations are important components of the controller which serve as the controlled variables at the coordination level. The inputs of the estimators are the process data of the column, e.g. temperature, pressure and flowrate. On the top level of the control hierarchical structure the quality of the products are controlled by manipulating the setpoint of the local controllers. Based on the analysis of the Controlled Variable - Manipulated Variable relationship, closed-loop quality control was achieved with PID controllers. The result of the analysis may form the basis of Advanced Process Controller implementation.
\end{abstract}

Keywords: distillation, multilevel control, MIMO, inferential, naphtha distillation, plant data

\section{Introduction}

Distillation is the most widely used separation technique in the chemical and petrochemical industries. Around $95 \%$ of the separation tasks of components are performed using distillation in the chemical industry, and the distillation units use approximately $3 \%$ of the total energy consumption of the world [1]. Therefore, the improvement of distillation controllers and processes is important because of their widespread use and huge levels of energy consumption. Distillation is a complex task because all of the equipment are Multiple Input, Multiple Output (MIMO) objects from a control point of view with strong interactions [2]. The performance of distillation controllers directly affects the productivity rates, utility usage and product quality. During the operation, attaining a sufficient level of product quality is the final goal. Hence, the precise calculation of the qualities is very important from an economic point of view.

In this work, the multilevel control structure of the naphtha redistillation column has been analyzed (Fig. 1). Furthermore, a simulator with the same local control structure as the existing distillation column in the Danube Refinery was created. The model was adapted according to the data of the sensors and laboratory measurements. The controlled quality values were provided by inferential calculations based on archived data of the unit. During the analyses a control structure was created which could be suitable for the quality control of the column, and also the resulting models can be used in the implementation of Advanced Process Controllers (APC).

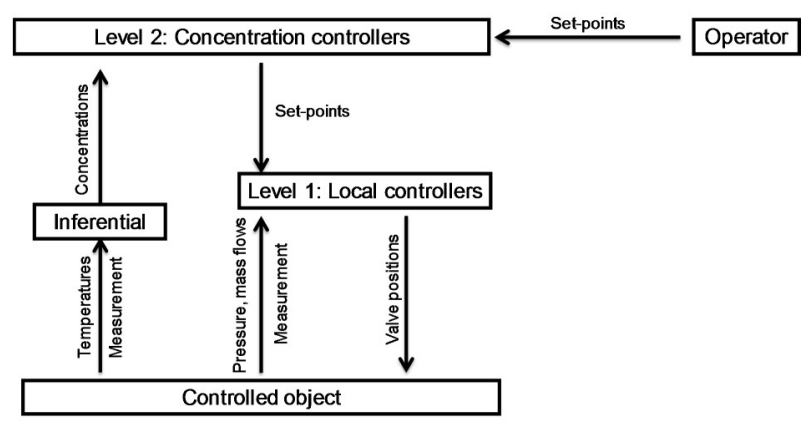

Figure 1. Structure of the control system

*Correspondence: Iszaboszhb@mol.hu 
Table 1. Disturbances

\begin{tabular}{|l|l|l|l|}
\hline Value type & Noise & Delay & Lag \\
\hline Mass flowrate & $1.0 \%$ & $15 \mathrm{~s}$ & $0 \mathrm{~s}$ \\
\hline Pressure & $0.2 \%$ & $0 \mathrm{~s}$ & $0 \mathrm{~s}$ \\
\hline Temperature & $0.3 \%$ & $30 \mathrm{~s}$ & $60 \mathrm{~s}$ \\
\hline Level & $1.0 \%$ & $60 \mathrm{~s}$ & $0 \mathrm{~s}$ \\
\hline
\end{tabular}

\section{Experimental}

For the analyses of dynamic responses a piece of commerical simulation software was used. Data evaluation and parameter identification of the inferential calculations were performed with $\mathrm{R}$ programming language.

\subsection{Separation task}

The column has two feeds, the light naphtha feedstock possesses an initial boiling point of $12{ }^{\circ} \mathrm{C}$ and a final boiling point of $150{ }^{\circ} \mathrm{C}$, while the boiling range of the heavy naphtha feedstock stretches from 57 to $197{ }^{\circ} \mathrm{C}$. The task of the column is to separate the two feeds into three different naphtha products. The specification of the product streams are the following: distillate final boiling point should be between 58 and $65^{\circ} \mathrm{C}$, the final boiling point of the side product should be between 87 and $147^{\circ} \mathrm{C}$, and the initial boiling point of the bottom product should be between 99 and $103^{\circ} \mathrm{C}$. The simulator was implemented using Aspen HYSYS ${ }^{\circledR}$ software. The structure of the simulator is shown in Fig. 2.

\subsection{Simulator}

The implementation of the column was achieved over two main steps. In the first step, a steady-state simulator of the column was developed. The structure of the simulator follows the process flow diagram in Fig. 2. The column is divided into two parts, the light feedstock is loaded into the upper section (Column 107), and the heavy feedstock is fed into the lower section (Column 102). The towers, air coolers and heat exchangers were simulated with rigorous blocks and the model was adapted to data of the sensors and laboratory measurements. In the second step, the dynamic simulator was created based on the steady-state model. During the implementation of the dynamic simulator the calculation blocks were defined from the sizes of the actual equipment, e.g. the parameters of the trays in the tower. In some cases, pseudo pieces of equipment had to be defined to achieve a more realistic simulator, e.g. the bottom of the columns were modelled with a vertical drum to create a more detailed model.

\subsection{Measurement Disturbances}

Before determining the parameters of the controller, noise and time delays were applied to the calculated values. The disturbaces were determined based on our

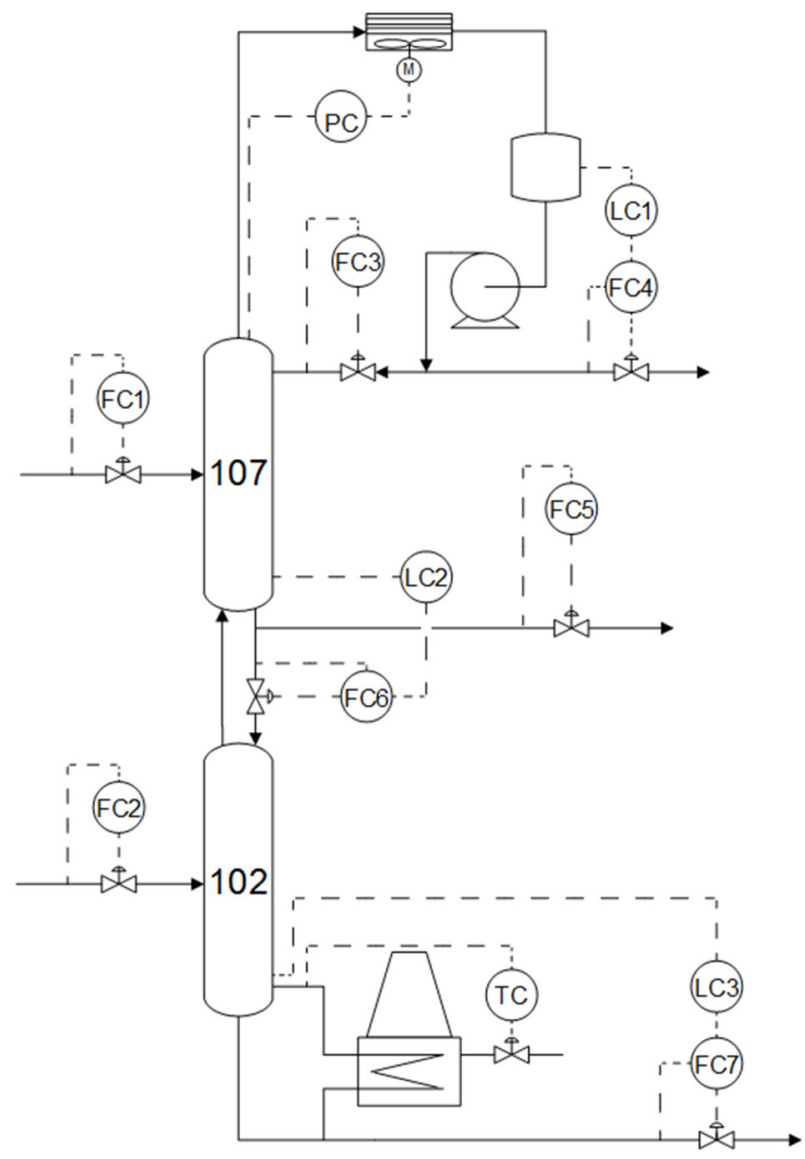

Figure 2. Structure of the simulator

previous experience. Transfer function blocks were used to simualte measuring instruments. Their parameters can be seen in Table 1. These signals were used later as controlled values.

\subsection{Control Structure of Column}

Fig. 1 represents the overall structure of controllers. On the lower level of the hierarchy the local controllers can be found. On this level, the controllers maintain the operating conditions (pressure and liquid level controllers) of the column and eliminate the disturbances (mass flowrate controllers) of the environment. The controller output variables are the valve positions and the process variables are the mass flowrates, liquid levels and pressure.

The structure of the local controllers can be seen in Fig.2, which is the same as the structure of the controller in the real column. The FC1 and FC2 controllers eliminate the fluctuation of the feed mass flowrate. The PC and the TC controllers compensate for weather changes and the fluctuation of fuel gas. The liquid level controllers (LC1, LC2 and LC3) were necessary to ensure normal operation because the refluxes and the boil-up flowrate would be zero if there is no liquid phase in the reflux drum and at the bottom of the columns [3]. PI controllers were applied at the local level.

The degree of separation is based on the sustenance of the temperature difference between 


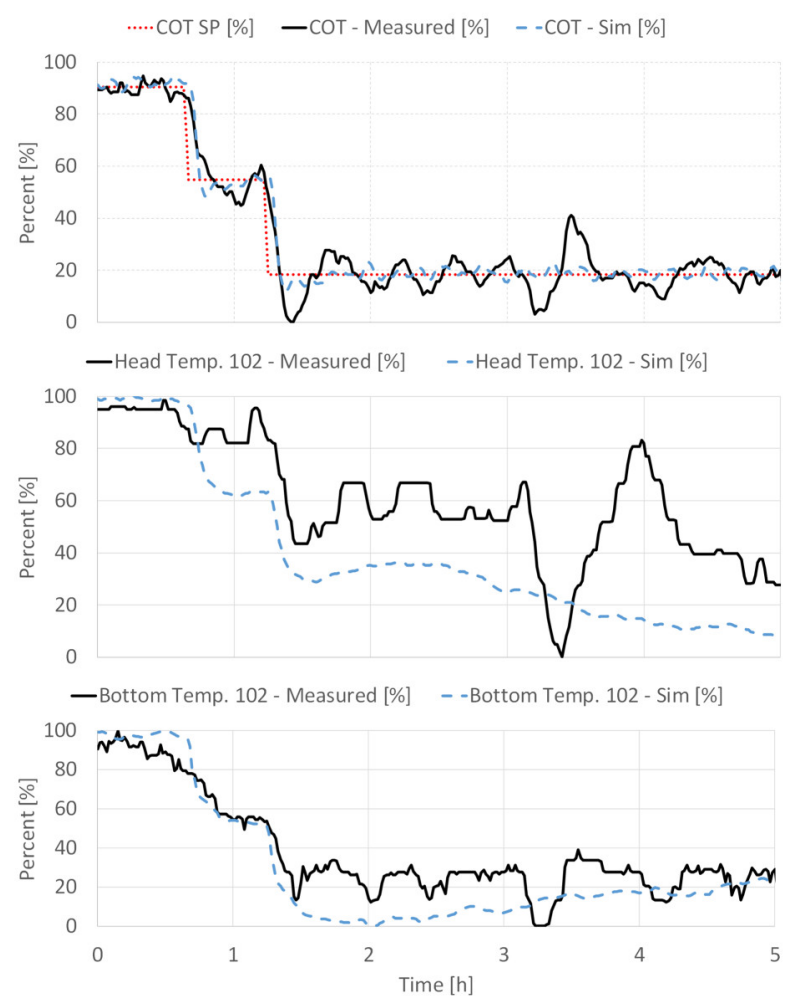

Figure 3. Validation of the Simulator

products. The main target of the operation is to achieve specified product qualities. The provision of online quality values for the control is an important task in the industry. One of the feasible solutions is to apply inferential calculations. Generally the inputs of these calculations are temperatures, because the quality of products is strongly correlated with the tray temperatures of the columns. Consequently, the temperature and quality controls serve the same purpose. Therefore, in this paper the quality of the products was controlled at the top level of the control hierarchy. The controller outputs on this level were the setpoints of the local controllers (FC3, FC5 and TC) and the controlled values were the outputs of the inferential calculations.

\section{Results and Analysis}

\subsection{Validation of the Simulator}

In the first analysis, the dynamic behavior of the simulator was validated. (The steady-state accuracy was validated during the construction of the model.) The model was compared to the historical data of the real column.

As Fig. 3 shows, the coil outlet temperature (COT) of the furnace was changed over two steps. During this process the top temperature of Column 107 was controlled. The head and bottom temperatures of Column 102 were analyzed, because the effect of the COT was significant on these parameters. The operating point of the real column was different from the

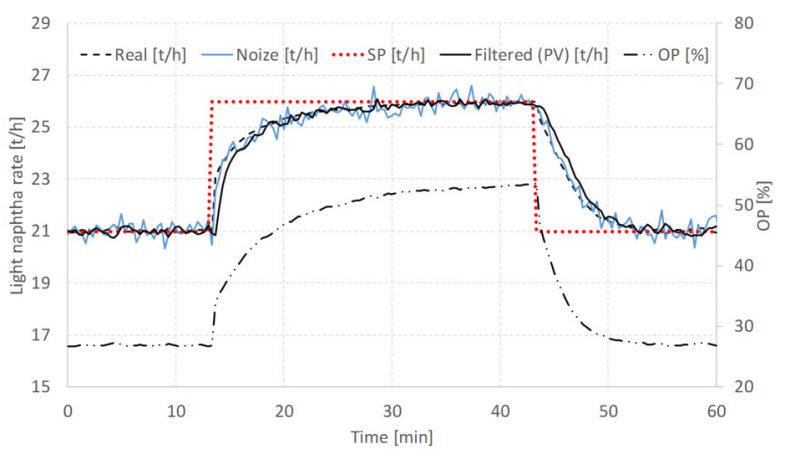

Figure 4. FC1 controller

simulated one, however, in this analysis only its dynamic behavior was evaluated. Therefore, in the simulator the setpoint of the COT was changed in the same direction and by the same amount as the measured data. The signals were normalized in order to compare the trends easily. It can be seen that the curves possess the same correlation in both the simulated and real columns. The dynamics of the responses were also identical in both cases, thus the simulator was found reliable for further analyses.

\subsection{Analysis of Local Controllers}

For the tuning of the local controllers previous experiences were drawn on [4]. It was assumed that the controllers exhibit no significant interactions so they can be tuned independently. Before determining the parameters of the controllers, filters were applied, hence, the dynamics of the loops were approximated to the real control loops.

The control loops were tuned in the following order: flowrate (FC1-7), the liquid level (LC1-3) and pressure (PC) controllers. In the last step the parameters of the coil outlet temperature controller (TC) were determined. For the loops, Honeywell equation B [5-6] was used, and the proportional and integrating parameters were determined using the built-in autotuner tool. After automatic tuning, the loops were tested and fine tuning was carried out to avoid fluctuation of the loops. The behavior of the $\mathrm{FC} 1$ is presented in Fig. 4. As the figure shows, the controllers follow the setpoint without exceeding it, which ensures a robust local controller system. The raw calculated signal, the signal loaded with noise and the filtered (controlled) signals are also presented in Fig.4. As the results show, the control of the raw values is stable and is the first signal to reach a setpoint.

\subsection{Inferential Calculations}

The quality estimators were created for the final boiling points of the distillate and the side product and for the initial boiling point of the bottom product. For the inferential fitting the laboratory and process data was used; the data was collected over a period of one year. In the case of the process data, all relevant measurement points of the column were considered (flowmeters, 

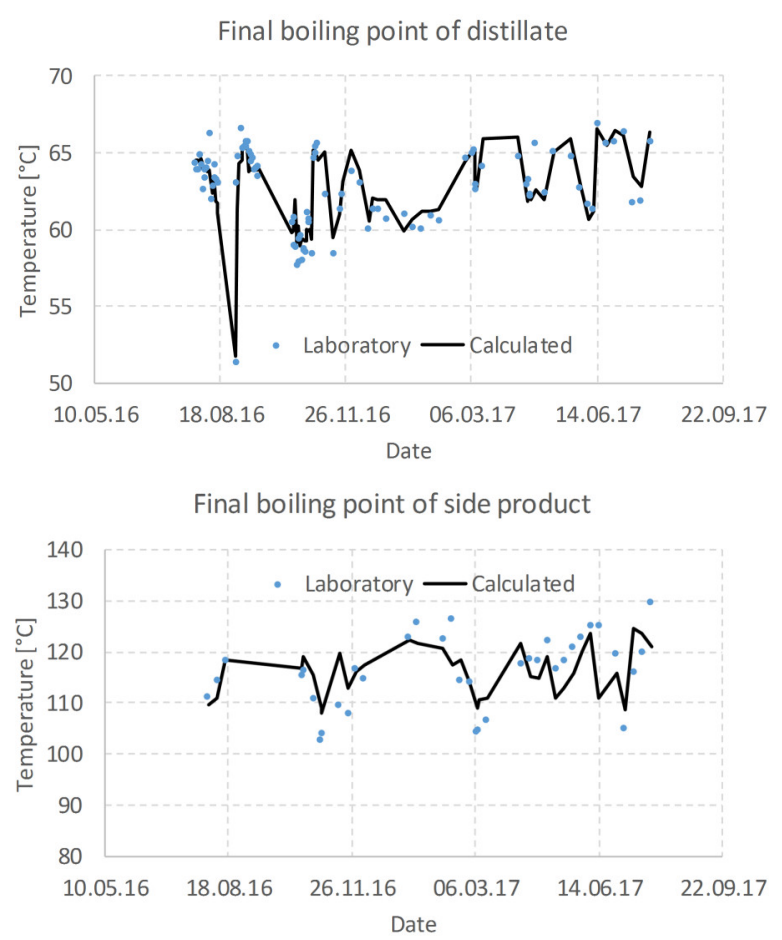

Initial boiling point of bottom product

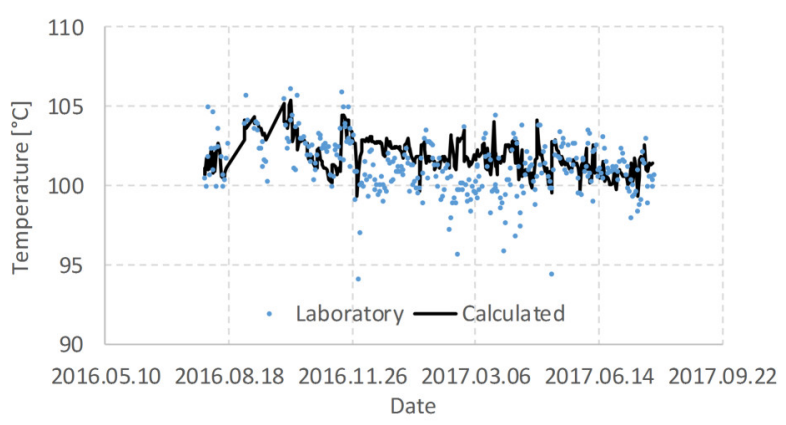

Figure 5. Performance of inferential calculations

temperature and pressure measurements). One hourlong periods were aggregated from the online data before each laboratory sample time. From these values pressure compensated temperatures (PCT) and ratios of the mass flowrates were also calculated.

The inputs of the equations (see Table 2) were determined using correlation analysis, thus the qualities were calculated from the most relevant values. The parameters of the equations were calculated using linear regression. The results of the fittings are presented in Fig.5.

Table 2. Input parameters of inferential calculations

\begin{tabular}{|l|l|c|}
\hline \multicolumn{1}{|c|}{ Inferential } & \multicolumn{1}{|c|}{ Input 1 } & \multicolumn{1}{c|}{ Input 2 } \\
\hline $\begin{array}{l}\text { Final boiling point of } \\
\text { distillate }\end{array}$ & $\begin{array}{l}\text { PCT of 107 head } \\
\text { temperature }\end{array}$ & \\
\hline $\begin{array}{l}\text { Final boiling point of } \\
\text { side product }\end{array}$ & $\begin{array}{l}\text { PCT of 107 bottom } \\
\text { temperature }\end{array}$ & $\frac{\text { Light naphtha }}{\text { Light feed }}$ \\
\hline $\begin{array}{l}\text { Initial boiling point } \\
\text { of bottom product }\end{array}$ & $\begin{array}{l}\text { PCT of 102 bottom } \\
\text { temperature }\end{array}$ & \\
\hline
\end{tabular}

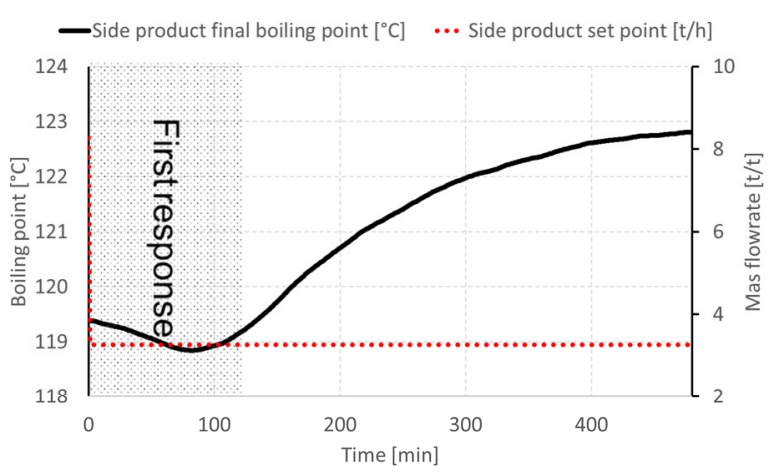

Figure 6. Open loop test CV2 - MV2

\subsection{Structure of Quality Controllers}

According to the separation task the controlled variables (CV) are: distillate final boiling point (CV1), sideproduct final boiling point (CV2) and bottom product initial boiling point (CV3). The manipulated variables are the following: setpoints of FC3 (MV1), FC5 (MV2) and TC (MV3). The structure of the quality controllers was determined with the help of the relative gain array (RGA) [7]. To create the array, a step test was performed for each manipulated variable (MV) in the simulator. The RGA is presented in Table 3. The elements of the matrix evaluate a possible loop with the given $\mathrm{MV}-\mathrm{CV}$ pair. If the element of the array is negative, closing other loops will reverse pairing gain. This configuration will become unstable if the other loops operate. If the element of the RGA exceeds one, interaction with other loops has an inhibiting effect. Closing other loops decreases pairing gain. If the value is between 0 and 1 then pairing gain will increase by closing the other loops; the interaction is the greatest at 0.5 . In the case of this pairing the loop should be tuned when the other loops are automated. If the RGA value is 1 then the other loops have no effect on the pairing gain. In the case of the CV1 the evident manipulated variable is MV1. The other two can be paired in two ways. According to the RGA, the obvious pairing should be CV2 - MV2 / CV3 - MV3. However, there is a primary effect between $\mathrm{MV} 2$ and $\mathrm{CV} 2$, and it possesses a negative gain. This behavior could make the control loop instable, or the settling time of the controlled object would be large. The dynamic responses are presented in Fig.6. In this analysis the MVs were stepped during the first minute. Only the local controllers were in closed loops during the analyzed period.

Table 3. Relative Gain Array

\begin{tabular}{|l|l|l|l|}
\hline & MV1 & MV2 & MV3 \\
\hline CV1 & 7.7 & -1.2 & -5.5 \\
\hline CV2 & -6.9 & 1.9 & 6.0 \\
\hline CV3 & 0.2 & 0.3 & 0.5 \\
\hline
\end{tabular}




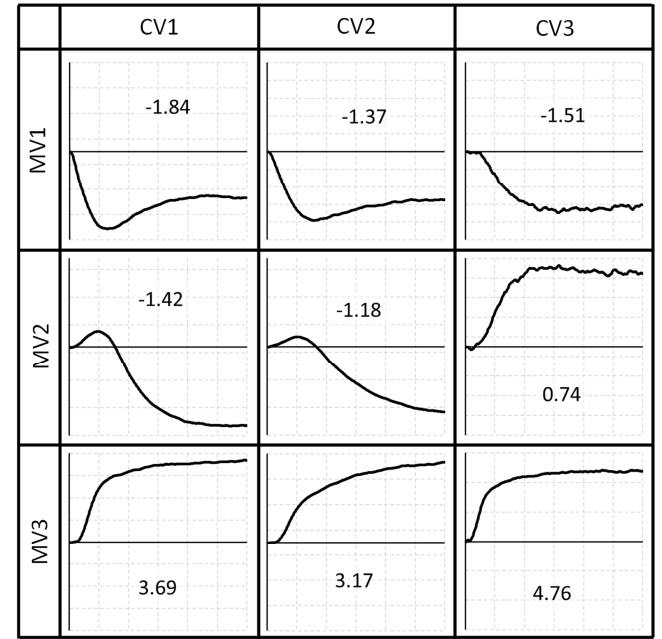

Figure 7. APC models

The following final control pairings were applied: CV1 - MV1, CV2 - MV3 and CV3 - MV2. According to this analysis quality control can be achieved using simple PID control loops. Therefore, the analysis of the closed-loop quality control in the following chapter was performed using only PID loops. This analysis was also the basis of an APC implementation. The initial APC models can be seen in Fig.7.

\subsection{Operation of Quality Controllers}

In this analysis the operation of the quality controllers was analyzed in the case of a disturbance. The mass flowrate of the light naphtha feed was changed at 5 o'clock. During the analyzed period all of the local and quality controllers were in closed loops. According to the results in Fig.8, the controller system can compensate for this change. In the figure the values of the MVs were normalized between their minimum and maximum limits.

In the case of CV1 this quality did not violate the specification limit, and the controlled variable was close to the setpoint after 2.5 hours. This parameter possessed the smallest peak of the three CVs at approximately 1.3 ${ }^{\circ} \mathrm{C}$. CV2 exhibited a peak at approximately $2{ }^{\circ} \mathrm{C}$, nevertheless, this was well within the specification limit so it did not violate it. The settling time was about 7.5 hours. CV3 exhibited a peak at approximately $3{ }^{\circ} \mathrm{C}$ which violated the specification limit. After 2.5 hours the $\mathrm{CV}$ once again exceeded the limit. The settling time was $\sim 15$ hours. As can be seen the outputs (OP) were moved after the settling of the CVs, but because of the long settling time the whole time period was not presented.
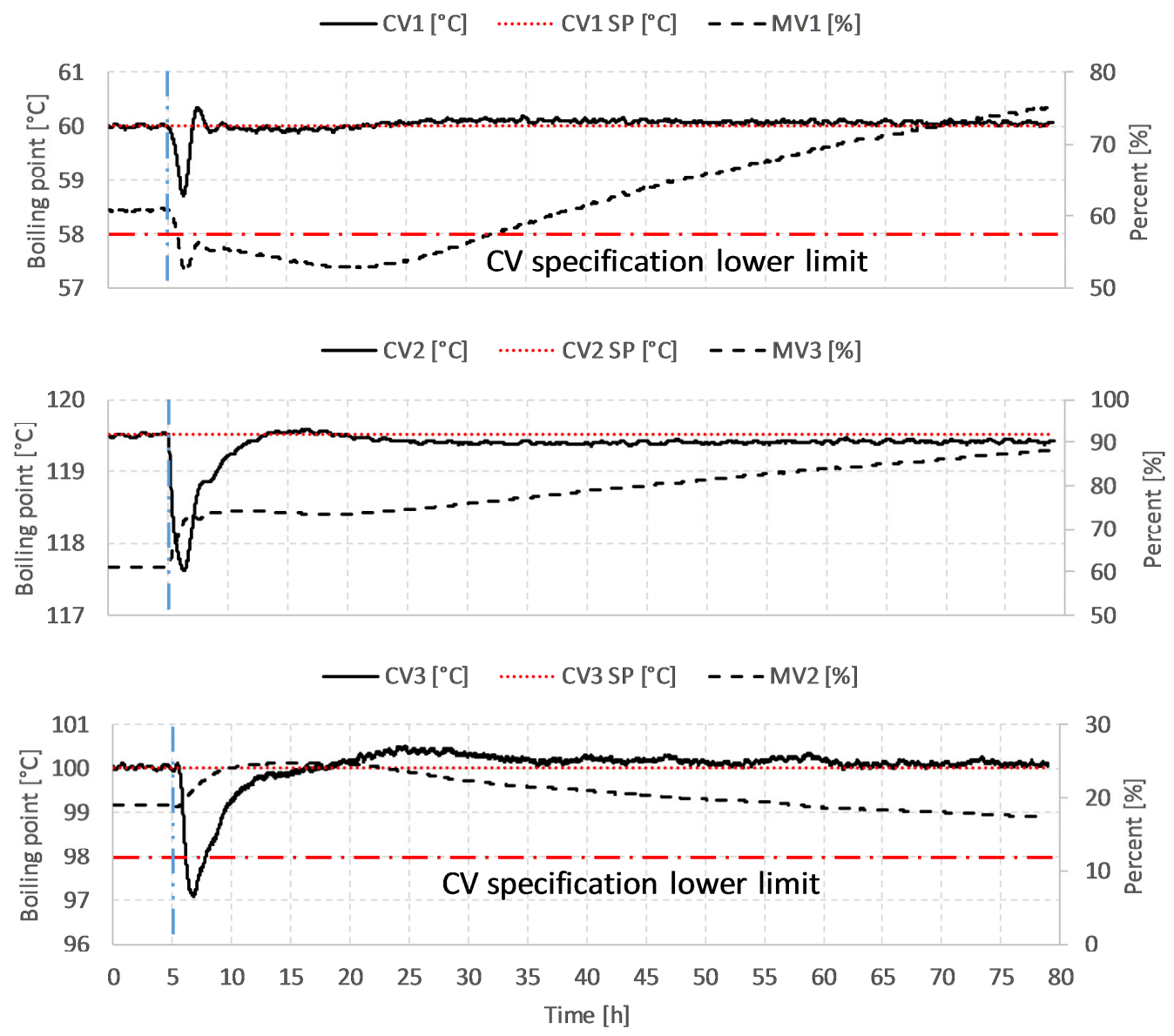

Figure 8. Operation of Quality Controllers 


\section{Conclusion}

For the analysis of the naphtha redistillation column at MOL Plc. the dynamic simulator of the unit was adapted to the data of the real equipment. The steadystate accuracy and the dynamic behavior of the model were evaluated. The simulator is reliable for the analysis of the column.

For the operation of the distillation column a twolevel control structure was implemented in the simulator. On the lower level of the control hierarchy controllers were created which facilitated normal operating conditions of the column (pressure and liquidlevel controllers) and eliminated the disturbances of the environment (mass flowrate controllers). To ensure quality signals, inferential calculations were created based on the historical data of the real column. The inputs of the calculations were mainly the temperature measurements of the columns. Hence, the controlled temperatures were chosen during the correlation analysis of the inferential calculations; on the top level of the control hierarchy the controlled variables were the outputs of the quality estimators.

The manipulated variables were the setpoints of the local controllers. The pairing of the manipulated and controlled variables should be defined carefully. The first aspect of the pairing was the gain between the variables, however, the dynamic responses were also considered. To eliminate the interaction and to improve the performance of the quality controller, decoupling [8] or a model predictive controller [9] was recommended.

The simulator-based column analysis can be a good foundation for an Advanced Process Controller. The CV-MV pairing and resulting single input-single output models can be used as initial models in Advanced Process Controllers.

Furthermore, the simulator can be used for the analysis of column operation issues in the plant. The resulting inferential calculations have already been implemented and are available for the operators to facilitate quality control.

\section{Acknowledgements}

We acknowledge the financial support of Széchenyi 2020 under the project EFOP-3.6.1-16-2016-00015.

\section{REFERENCES}

[1] Mansour, K.; Mansour, E.: Rigorous optimization of heat-integrated and Petlyuk column distillation configurations based on feed conditions, Clean Techn. Environ. Policy, 2009 11(1), 107-113 DOI: 10.1007/s10098-008-0171-6

[2] Skogestad, S.; Morari, M.: The dominate time constant for distillation columns, Computers and Chemical Engineering, 1987 11(6), 607-617 DOI: 10.1016/0098-1354(87)87006-0

[3] Buckley, P.S.: Techniques of Process Control, (Wiley, London, United Kingdom) 1964 ISBN10:0882757776

[4] Szabó, L.; Németh, S.; Szeifert, F.: Three-Level Control of a Distillation Column, Engineering, 2012 4(10), 675-681 DOI: 10.4236/eng.2012.410086

[5] Honeywell: Application Module Algorithm Engineering Data, 1-800 343-0228

[6] Aspentech: Aspen HYSYS Unit Operations Reference Guide, Version Number: V10

[7] Skogestad, S.: Dynamics and Control of Distillation Columns: A Tutorial Introduction, Chemical Engineering Research and Design, 1997 75(6), 539-562 DOI: 10.1205/026387697524092

[8] Benz, S.J.; Scennal, N.J.: An Extensive Analysis on the Start-up of a Simple Distillation Column with Multiple Steady States, The Canadian Journal of Chemical Engineering, 2002 80(5), 865-881 DOI: $10.1002 /$ cjce. 5450800510

[9] Luyben, W.L.: Process Modeling, Simulation, and Control for Chemical Engineers (McGraw-Hill, New York, USA) 1990 ISBN-10:0070391599 